\title{
On the effect of moisture on the detection of tropospheric turbulence from in situ measurements
}

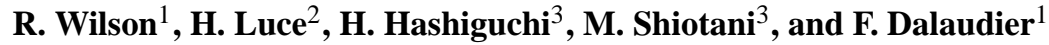 \\ ${ }^{1}$ UPMC Univ Paris 06, LATMOS-IPSL, UMR8190, CNRS/INSU, 75005, Paris, France \\ ${ }^{2}$ Univ. du Sud Toulon-Var, 83957, La Garde Cedex, France \\ ${ }^{3}$ Research Institute for Sustainable Humanosphere, Kyoto University, Uji, Japan
}

Correspondence to: R. Wilson (richard.wilson@upmc.fr)

Received: 16 October 2012 - Published in Atmos. Meas. Tech. Discuss.: 8 November 2012

Revised: 11 February 2013 - Accepted: 1 March 2013 - Published: 14 March 2013

\begin{abstract}
The present paper addresses the detection of turbulence based on the Thorpe (1977) method applied to an atmosphere where saturation of water vapor occurs. The detection method proposed by Thorpe relies on the sorting in ascending order of a measured profile of a variable conserved through adiabatic processes, (e.g. potential temperature). For saturated air, the reordering should be applied to a moist-conservative potential temperature, $\theta_{\mathrm{m}}$, which is analogous to potential temperature for a dry (subsaturated) atmosphere. Here, $\theta_{\mathrm{m}}$ is estimated from the Brunt-Väisälä frequency derived by Lalas and Einaudi (1974) in a saturated atmosphere. The application to balloon data shows that the effective turbulent fraction of the troposphere can dramatically increase when saturation is taken into account. Preliminary results of comparisons with data simultaneously collected from the VHF Middle and Upper atmosphere radar (MUR, Japan) seem to give credence to the proposed approach.
\end{abstract}

\section{Introduction}

Several studies dealing with the application of the Thorpe (1977) method for detecting turbulence from balloon data were recently published by Clayson and Kantha (2008); Nath et al. (2010); Alappattu and Kunhikrishnan (2010); Balsley et al. (2010) and Kantha and Hocking (2011). The Thorpe method consists in sorting, in ascending order, the measured profile of potential temperature (in the atmosphere), or potential density (in the ocean or lakes), so as to obtain a reference profile that is stable everywhere. This reference profile corresponds to the minimum in potential energy reachable from measurements. The differences in the measured and sorted profiles are expected to be related to overturning events due to turbulence, giving rise to (static) instabilities or to stirring.

In practice, instrumental noise can produce spurious overturns, especially in regions of weak static stability. Consequently, noise effects can produce misleading results if they are not carefully appreciated. This topic was thoroughly addressed by, e.g. Ferron et al. (1998); Johnson and Garrett (2004); Gargett and Garner (2008) for applications to oceans, and by Wilson et al. $(2010,2011)$ for applications to the atmosphere.

The Thorpe sorting must be applied to vertical profiles of a conservative quantity through adiabatic processes. In the ocean, the Thorpe sorting is applied to potential density profiles measured by Conductivity Temperature Depth (CTD) sensors. These profiles are retrieved from temperature, pressure and salinity measurements. In a humid (but unsaturated) atmosphere, the Thorpe sorting is applied to potential temperature profiles. For an atmosphere where water vapor reaches saturation, upward motions imply water condensation and then release of latent heat, making the air parcels warmer than for a dry adiabatic expansion. Consequently, the static stability in saturated air is always lower than the static stability in subsaturated air. As a result, a saturated layer can be unstable but erroneously interpreted as stable if assumed to be dry. Therefore, the Thorpe sorting should be applied to profiles of a conservative quantity taking both states of the atmosphere into account: saturated and subsaturated. An effective potential temperature should depend on the saturation 
mixing ratio where air is saturated. This quantity somehow plays a role similar to salinity in the oceans.

The present paper first aims at explaining how to tackle the problem of air saturation effects when applying the Thorpe sorting to tropospheric data. The impact of saturation on turbulence detection is then evaluated by applying algorithms described by Wilson et al. (2011) to profiles measured by radiosondes. The identification of the mechanisms generating the observed turbulence is out of the topic of the present paper but could be the issue of future works.

A field campaign was conducted at Shigaraki MU Observatory (Japan) in September 2011. Thirty six Vaisala RS92SGP radiosondes launched during night time (in order to avoid solar insolation of the sensors) were considered in the present evaluation. Concurrent turbulence observations made by the VHF (46.5 MHz) Middle and Upper atmosphere radar (MUR) were performed and some observation results were used here for evaluating the proposed approach.

\section{The moist-conservative potential temperature $\theta_{\mathrm{m}}$}

When the atmosphere is dry, or not saturated (the effect of water vapor being found to be negligible in the free atmosphere, at least for mid-latitude conditions), the potential temperature $\theta(\mathrm{K})$ is a conservative variable during reversible adiabatic processes. Its expression at altitude $z_{i}$ is calculated from the relation

$\theta\left(z_{i}\right) \equiv \theta[i]=T[i]\left(\frac{P_{0}}{P[i]}\right)^{R / c_{\mathrm{pd}}}$,

where $T[i](\mathrm{K})$ and $P[i](\mathrm{hPa})$ are the temperature and pressure at level $z_{i}, P_{0}=1000 \mathrm{hPa}$ is the pressure at the reference level. From a practical point of view, the direct calculation of $\theta$ from Eq. (1) is equivalent to the integration of the empirical vertical gradient of potential temperature, for example:

$\theta[i]=\theta[0]+\sum_{k=0}^{i-1}\left(\frac{\partial \theta}{\partial z}\right)_{k} \Delta z=\theta[i-1]+\left(\frac{\partial \theta}{\partial z}\right)_{i-1} \Delta z$

where $z_{0}$ is the altitude of the ground level, and $\Delta z$ the (constant) vertical sampling of the measurements. The vertical gradient of potential temperature at level $z_{k}$ is estimated from

$$
\left(\frac{\partial \theta}{\partial z}\right)_{k}=\frac{\theta[k+1]-\theta[k]}{\Delta z}
$$

Because the squared Brunt-Väisälä frequency for dry air is defined by $N_{\mathrm{d}}^{2}[k]=\frac{g}{\theta[k]}\left(\frac{\mathrm{d} \theta}{\mathrm{d} z}\right)_{k}$ (where $g$ is the gravitational acceleration, approximated as a constant), Eq. (2) can be written as

$\theta[i]=\theta[i-1]\left(1+N_{\mathrm{d}}^{2}[i-1] \frac{\Delta z}{g}\right)$.
$N_{\mathrm{d}}^{2}$ can also be expressed as a function of temperature $T$ and the dry adiabatic lapse rate $\Gamma_{\mathrm{d}}$ :

$N_{\mathrm{d}}^{2}=\frac{g}{T}\left[\left(\frac{\partial T}{\partial z}\right)+\Gamma_{\mathrm{d}}\right]$,

with

$\Gamma_{\mathrm{d}}=\frac{g}{c_{\mathrm{pd}}}\left(\frac{1+q_{\mathrm{v}}}{1+q_{\mathrm{v}} \frac{c_{\mathrm{pv}}}{c_{\mathrm{pd}}}}\right)$,

where $q_{\mathrm{v}}$ is the water vapor mixing ratio $(\mathrm{g} / \mathrm{g})$, and $c_{\mathrm{pv}}$ and $c_{\mathrm{pd}}$ are the specific heats for water vapor and dry air, respectively. The latter expression for the dry adiabatic lapse rate includes the small effect due to the presence of water vapor (Emanuel, 1994).

For saturated (cloudy) air, Durran and Klemp (1982) and Emanuel (1994) showed that the precise condition for static instability is determined by the sign of the square of the socalled moist Brunt-Väisälä frequency rather than by the sign of $\frac{\partial \theta_{\mathrm{e}}}{\partial z}$, where $\theta_{\mathrm{e}}$ is the equivalent potential temperature. $N_{\mathrm{m}}^{2}$ is given by (Lalas and Einaudi, 1974; Durran and Klemp, 1982)

$N_{\mathrm{m}}^{2} \approx \frac{g}{T}\left[\left(\frac{\partial T}{\partial z}\right)+\Gamma_{\mathrm{m}}\right]\left[1+\frac{L_{\mathrm{V}} q_{\mathrm{s}}}{\mathrm{RT}}\right]-\frac{g}{1+q_{\mathrm{w}}}\left(\frac{\mathrm{d} q_{\mathrm{w}}}{\mathrm{d} z}\right)$,

where $L_{\mathrm{V}}$ is the latent heat of vaporisation of liquid water or ice, approximately constant for the temperatures met in the lower atmosphere. $q_{\mathrm{w}}=q_{\mathrm{L}}+q_{\mathrm{s}}$ is the total water mixing ratio where $q_{\mathrm{L}}$ is the liquid water or ice mixing ratio and $q_{\mathrm{s}}$ is the saturation mixing ratio.

In Eq. (7), $\Gamma_{\mathrm{m}}$ is the moist saturated lapse rate (Durran and Klemp, 1982):

$\Gamma_{\mathrm{m}}=\frac{g}{c_{\mathrm{pd}}}\left(1+q_{\mathrm{w}}\right) \times\left[1+\frac{c_{\mathrm{pv}} q_{\mathrm{s}}+c_{\mathrm{w}} q_{\mathrm{L}}}{c_{\mathrm{pd}}}+\frac{\gamma L_{\mathrm{V}}^{2} q_{\mathrm{s}}}{c_{\mathrm{pd}} \mathrm{RT}^{2}}\left(1+\frac{q_{\mathrm{s}}}{\gamma}\right)\right]^{-1}$,

where $c_{\mathrm{w}}$ is the specific heat for liquid (or ice) water, and $\gamma \approx 0.622$. As assumed by Durran and Klemp (1982), and because of the lack of information about the saturation total water mixing ratio in the clouds, we set $\mathrm{d} q_{\mathrm{w}} / \mathrm{d} z=\mathrm{d} q_{\mathrm{s}} / \mathrm{d} z$ in Eq. (7), and the contribution of $q_{\mathrm{L}}$ is neglected in the other terms of expressions (7) and (8).

For detecting convective instabilities in saturated air, $N_{\mathrm{d}}^{2}$ must be replaced by $N_{\mathrm{m}}^{2}$. The vertical integration of Eq. (4) with $N_{\mathrm{m}}^{2}$ instead of $N_{\mathrm{d}}^{2}$ provides a moist potential temperature, $\theta_{\mathrm{m}}$. It slightly differs from other moist potential temperatures reviewed by Durran and Klemp (1982), but appears to be convenient for applying the Thorpe method in a saturated atmosphere.

The Thorpe sorting is thus applied to a "composite potential temperature" profile (hereafter noted $\theta_{*}$ ) computed from Eq. (4), by using $N_{\mathrm{d}}^{2}$ for subsaturated air, and $N_{\mathrm{m}}^{2}$ for saturated air. Of course, $\theta_{*}$ does not refer to a conservative quantity throughout the overall profile. It is rather defined as a thermodynamic variable which is adapted for applying the Thorpe sorting. 


\section{Identification of the saturated regions}

The calculation of $\theta_{*}$ first requires the identification of the saturated regions using relative humidity $(\mathrm{RH})$ profiles measured by radiosondes. As described by, e.g. Miloshevich et al. (2004), the relative humidity measured by the radiosondes is calculated with respect to liquid water. For heights above the freezing point, saturation over ice must be addressed. The saturation pressure of water over ice, $e_{\mathrm{i}}$, can be estimated from the empirical expression given by Murphy and Koop (2005) (and references therein):

$e_{\mathrm{i}}(T)=\exp \left(28.9074-\frac{6143.7}{T}\right)$

where $T$ is in $\mathrm{K}$ and $e_{\mathrm{i}}$ in Pa. Equation (9) is valid for negative temperatures down to $-80^{\circ}$. For heights above the freezing point, the measured RH should be multiplied by $e_{\mathrm{w}} / e_{\mathrm{i}}$ so that $\mathrm{RH}$ sat $=100 \%$. For estimating $e_{\mathrm{w}}$, we used the Goff-Gratch equation recommended by the World Meteorological Organization (Goff, 1957).

In practice, accurate measurements of humidity are difficult (e.g. Nash et al., 2010) and values of RH vary around the saturation thresholds in clouds. Various systematic (dry) biases were identified for Vaisala radiosondes and corrections by software were proposed by e.g. Miloshevich et al. (2004, 2009). Nevertheless, a number of cloud layers would not be detected if the aforementioned criterion was strictly used. Empirical methods based on comparisons with other instruments were proposed by e.g. Wang and Rossow (1995); Poore et al. (1995) and Zhang et al. (2010). These empirical methods are evolving with the improvements in modern humidity sensors.

In order to appreciate the impact of saturation on the detection of turbulence, we applied the empirical method recently proposed by Zhang et al. (2010) for detecting clouds from Vaisala RS92SGP radiosondes. Drawing upon a method described by Wang and Rossow (1995), Zhang et al. (2010) selected atmospheric layers as saturated if they satisfied the two following conditions (among other refinements that we did not consider for simplicity):

$\min (\mathrm{RH}) \geq \mathrm{RH}_{\min }$ everywhere, and

$\max (\mathrm{RH}) \geq \mathrm{RH}_{\max }$ somewhere,

where $\mathrm{RH}$ is computed with respect to ice if $T<0^{\circ} \mathrm{C}$. $\mathrm{RH}_{\min }$ and $\mathrm{RH}_{\max }$ are two thresholds on $\mathrm{RH}$. While Wang and Rossow (1995) used constant thresholds (RH $\min =84 \%$ and RH max $=87 \%)$, Zhang et al. (2010) defined thresholds decreasing with altitude, from $95 \%(92 \%)$ to $80 \%$ (75\%), respectively. The clouds detected from their thresholds were shown to be quite consistent with the results of observations from remote sensing techniques (e.g. Fig. 7 of Zhang et al., 2010).

It must be noted that the derivations of $N_{\mathrm{d}}^{2}$ and $N_{\mathrm{m}}^{2}$ are made for dry and saturated airs separately. These theoretical
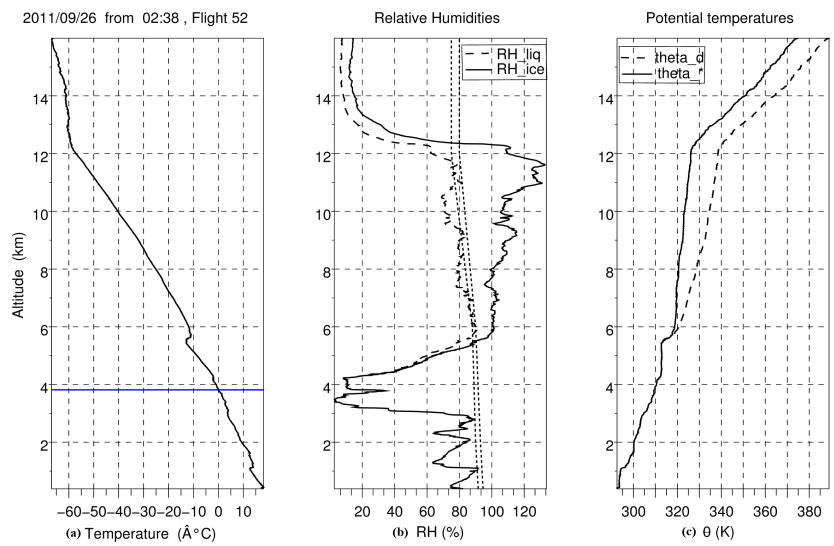

Fig. 1. (Left) Temperature profile for flight 52 (32nd flight used). The temperature $T=0{ }^{\circ} \mathrm{C}$ underneath the altitude of $4.0 \mathrm{~km}$ is emphasized by the horizontal line. (Center) The corresponding profiles of relative humidity RH (\%) over liquid water (solid line) and over ice (dashed line). The dotted lines show the Zhang et al. (2010) humidity thresholds. (Right) The corresponding profiles of potential temperature $\theta$ (dashed line) and of the composite potential temperature $\theta_{*}$ (solid) (see text for more details).

derivations fail to express the stability at condensation levels and at cloud edges (i.e. at the limit between clear and saturated airs). It is assumed that this problem will not significantly affect our results.

\section{Results}

A field campaign was conducted during September 2011 at the Shigaraki MU Observatory ( $34.85^{\circ} \mathrm{N}, 136.10^{\circ} \mathrm{E}$, Japan). MUR was continuously operated in range-imaging mode using frequency diversity devoted to improving its range resolution, e.g. (Luce et al., 2006). The carrier frequency of MUR is $46.5 \mathrm{MHz}$ so that it is mainly sensitive to clear air refractive index fluctuations at half the radar wavelength in size (i.e. the Bragg scale), even in presence of clouds or weak precipitations (less than $4 \mathrm{~mm} \mathrm{~h}^{-1}$ according to Campos et al., 2007). Therefore, small-scale refractivity turbulence can be monitored by MUR in both clear air and cloudy conditions.

Depending on the anisotropy of the refractive index irregularities at the Bragg scale, VHF radar echoes can strongly depend on the zenith angle of the radar beam direction, and, to a lesser extent, to the azimuth (e.g. Worthington et al., 1999; Hirono et al., 2004). A weak dependence of echo power with the radar beam direction strongly suggests that isotropic turbulent scatter is the dominant radar backscattering mechanism (e.g. Röttger and Liu, 1978). This property is important for the present context, as we shall see later.

In addition, in situ data from 59 RS92G Vaisala radiosondes (thirty-six during night periods) were gathered at the observatory in support of the radar observations. The Vaisala processing software can provide both raw and processed data 
Dry Atmosphere : LR52

(a)

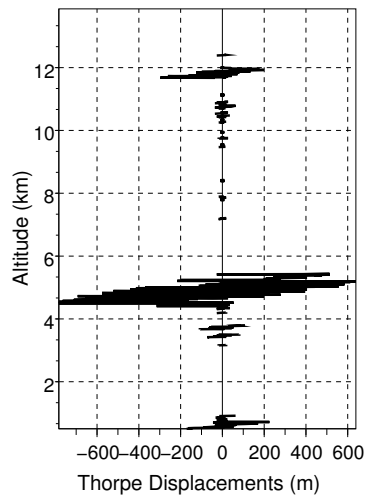

\section{.}

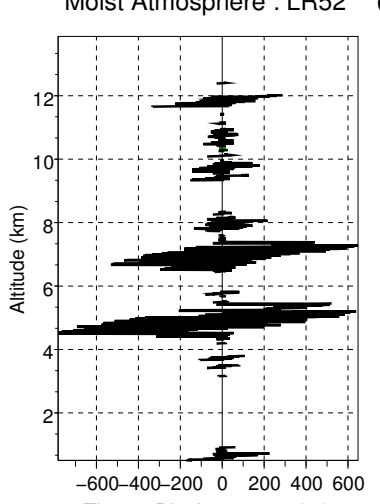

Thorpe Displacements $(\mathrm{m})$

Potential temperature $(\mathrm{K})$

Potential temperature $(\mathrm{K})$
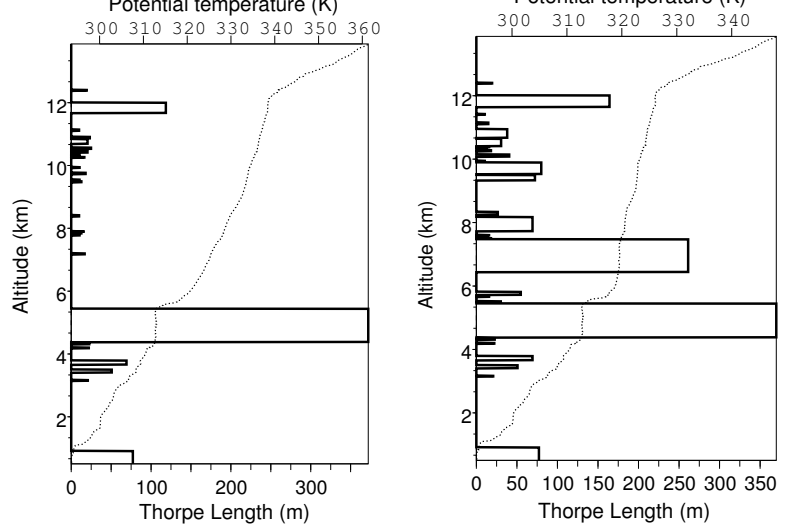

Fig. 2. (a) Thorpe displacements for the detected overturning events in flight 52 (top panel) and the corresponding Thorpe lengths (bottom panel) for a dry atmosphere. The bottom panel also shows the $\theta$ profile (dotted line). (b) Same as (a), but by including moisture effects and by applying the Zhang et al. (2010) criterion. The bottom panel also shows the $\theta_{*}$ profile (dotted line).

at a frequency sampling of $1 \mathrm{~Hz}$ and $2 \mathrm{~Hz}$, respectively. For our purpose, the raw data were used and re-processed using methods described by Wilson et al. (2011). The rms value of the noise level on the temperature measurements was $\sigma_{N} \sim 3 \times 10^{-2} \mathrm{~K}$. In addition, the balloons were underinflated so that most profiles were obtained at a vertical resolution of 3-5 m only (instead of $\sim 10 \mathrm{~m}$ or more for the standard processed profiles sampled at $2 \mathrm{~Hz}$ ). A similar method has already been used by Balsley et al. (2010) for boundary layer observations.

\subsection{Case study}

As an illustration, Fig. 1 displays the vertical profiles of temperature (Fig. 1a), relative humidity over liquid and ice (Fig. 1b) and $\theta$ and $\theta_{*}$ (Fig. 1c) for flight 52 (26 September $201102: 38 \mathrm{LT}$ ). Saturation over ice was likely to occur in the height range $5.5-12 \mathrm{~km}$ despite the fluctuating behavior of the RH profiles, close to or above $100 \%$. A thick cloud layer was present according to the Zhang et al. (2010)

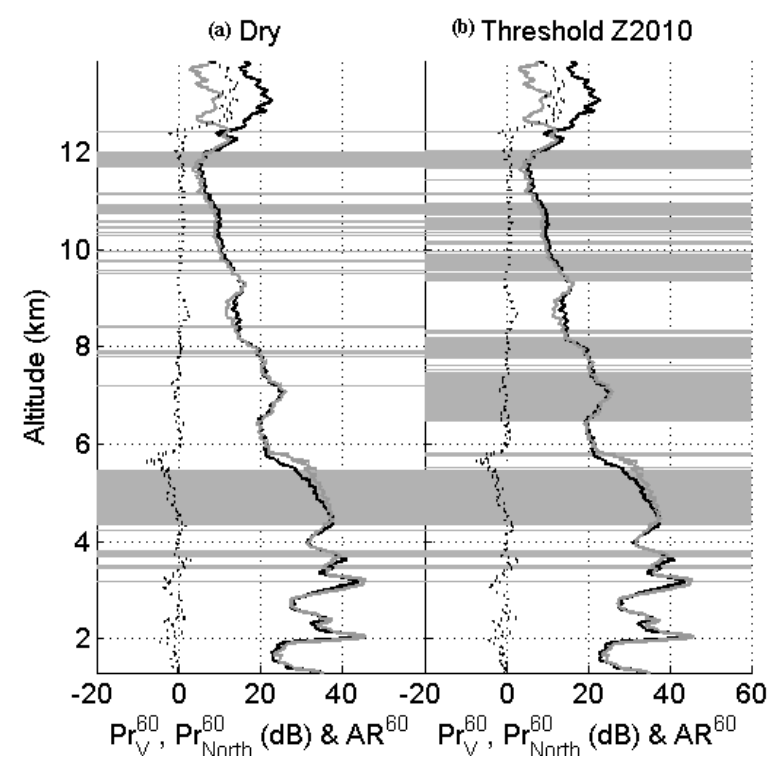

Fig. 3. (a) Vertical echo power profiles (averaged over $60 \mathrm{~min}$ during the balloon flight 52 and corrected from range attenuation effects) measured by MUR at vertical (black) and oblique (gray) $\left(10^{\circ}\right.$ off zenith) incidences. The dotted black curve shows the aspect ratio i.e. the ratio between the vertical and oblique echo powers. The light gray rectangles show the detected overturning events by assuming a dry atmosphere. (b) Same as (a), but balloon data analyses were performed by including the moisture effects.

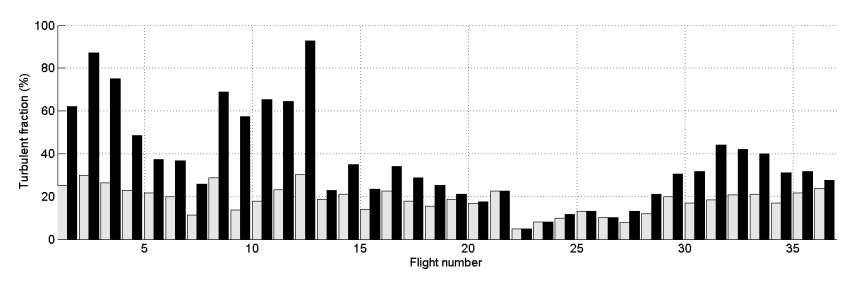

Fig. 4. Fraction of depth of all the detected turbulent overturns (i.e. total depth/troposphere depth) for each balloon flight for a dry troposphere (gray line) and after including the saturation effects (black line).

criterion. The presence of high-level clouds was confirmed by satellite IR images (not shown). In addition, a humid frontal zone was also identified from meteorological charts and high levels of humidity were diagnosed from NCEP data re-analysis above the altitude of $\sim 6.0 \mathrm{~km}$ (not shown).

As expected, the stability is reduced (with respect to dry air conditions) in the height ranges where air is assumed to be saturated (5.5-12 km) (Fig. 1c). The vertical gradients of $\theta$ and $\theta_{*}$ profiles will only differ in the regions where saturation occurs. Indeed, the two profiles in dry regions are identical and only differ when a saturated layer in encountered, i.e. above the altitude of $5.7 \mathrm{~km}$ in Fig. 1c.

Figure 2 shows the overturning events selected from the $\theta$ and $\theta_{*}$ profiles (frame a and $\mathbf{b}$, respectively). The top panels 
of Fig. 2 show the Thorpe displacements $(\mathrm{m})$ for the selected turbulent layers according to the criterion described by Wilson (2010). The bottom panels show the corresponding Thorpe lengths, $L_{\mathrm{T}}(\mathrm{m})$, estimated for each event. The decrease of stability is such that a large fraction of the cloud above the altitude of $6.0 \mathrm{~km}$ is detected as turbulent.

Figure 3 displays the corresponding vertical profiles of MUR echo power $P$ averaged over 60 min during the balloon flight and corrected from the range $r$ attenuation effects (i.e. $\left.P \times r^{2}\right)$ in $\mathrm{dB}$ (arbitrary levels) measured with the vertical beam and the Northward beam titled $10^{\circ}$ off zenith. The radar aspect ratio, defined as $P_{\text {Vert }} / P_{\text {North }}(\mathrm{dB})$ is also shown. The gray rectangles show the selected overturning regions from $\theta$ and $\theta_{*}$ profiles (Fig. 3a and b, respectively). The radar echo power profiles exhibit smooth fluctuations and are similar at vertical and oblique incidences in the height range $4.0-12.0 \mathrm{~km}$, consistent with nearly isotropic turbulence. Such characteristics of the radar echoes in cloudy or precipitating regions have already been reported by Vaughan and Worthington (2000) and are fully consistent with the turbulence statistics made in cloudy and/or precipitating regions by Hocking and Hocking (2007). The results obtained from $\theta$ (dry) profile only show sparse and thin overturning regions in the saturated layer $(6-12 \mathrm{~km})$. The same analysis from the $\theta_{*}$ profile rather reveals several deep turbulent layers within this saturated (cloudy) region. The vertical extent of these layers is consistent with the extent of saturated region and with the isotropy of the smooth radar echo power profiles. This result is thus a strong indication that the use of $\theta_{*}$ profile is more relevant than the use of $\theta$ profile for detecting turbulent layers in a moist atmosphere.

\subsection{Statistics}

Statistical results from the data collected from the 36 flights performed during night periods are shown in Fig. 4. The turbulent fractions, i.e. the ratios of total depths of the regions selected as turbulent to the depth of the overall troposphere are displayed. The gray and black bars show the turbulent fractions for each flight by assuming a dry atmosphere and by including the saturation effects, respectively. On average, the turbulent fraction reaches $34.2 \%$ of the troposphere when saturation is taken into account. It is only $18.6 \%$ if the overall troposphere is assumed to be dry. However, the total number of selected events in the $\theta_{*}$ profiles is less than in the $\theta$ profiles (854 instead of 1044) because some of them merged together and are thus deeper: the mean and median depths are $223 \mathrm{~m}$ and $81 \mathrm{~m}$, instead of $99 \mathrm{~m}$ and $60 \mathrm{~m}$, respectively.

Because saturation frequently occurred during the 12 first flights, the dry air hypothesis would lead to a strong underestimate of the turbulent fraction of the troposphere. This fraction can exceed $80 \%$ when saturation is taken into account (see flights 2 and 12) but is less than $30 \%$ when assuming a dry air. After the 12th flight, the troposphere became drier (i.e., almost no cloud) and little or no difference was found between the turbulent fractions. After the 31st flight, the turbulent fractions increase when including saturation effects due to the passage of a moist upper level front (not shown).

Of course, these quantitative estimates depend critically on RH measurements, which are known to be somewhat unreliable. These statistical results should therefore be considered with some caution. However, the overall method of detection should become more reliable with the improvement of humidity sensors.

\section{Summary and conclusions}

The present paper aimed to demonstrate the need for including the effects of air moisture when detecting temperature turbulence in the troposphere from in situ (balloon) measurements by using the Thorpe method. The effect of saturation was not considered in any previous work on the topic. Since the Thorpe method is based on sorting the profile of a conservative (and monotonic) variable, our study suggests that the relevant variables are the potential temperature, $\theta$, for subsaturated air and a moist potential temperature $\theta_{\mathrm{m}}$ for saturated air. The moist potential temperature $\theta_{\mathrm{m}}$ is calculated from the moist Brunt-Väisälä frequency defined by Lalas and Einaudi (1974) and demonstrated to be accurate by Durran and Klemp (1982). An empirical method proposed by Zhang et al. (2010) was applied for determining the saturated layers from Vaisala RS92 radiosonde measurements. Air saturation reduces static stability with respect to dry air (the well-known conditional instability) so that small-scale turbulence triggered by convective or dynamic instabilities is more likely to develop in clouds. As a matter of fact, smallscale turbulence is commonly observed in both stratiform or cumuliform clouds (e.g. Houze, 1993). Therefore, as expected, the detected turbulent fraction of a (cloudy) troposphere is significantly larger if saturation effects are properly taken into account when applying the Thorpe method.

Acknowledgements. Financial support for the stay of two authors (R. Wilson and H. Luce) was provided by RISH during the field campaign. Part of this work was carried out during the stay of H. Luce at RISH funded by the National Institute of Information and of Communications Technology (NICT, Japan). Radiosondes were funded by LATMOS.

Edited by: S. Malinowski



The publication of this article is financed by CNRS-INSU. 


\section{References}

Alappattu, D. P. and Kunhikrishnan, P. K.: First observations of turbulence parameters in the troposphere over the Bay of Bengal and the Arabian Sea using radiosonde, J. Geophys. Res., 115, D06105, doi:10.1029/2009JD012916, 2010.

Balsley, B., Kantha, L., and Colgan, W.: On the use of Slow Ascent Meter-Scale (SAMS) Radiosondes for observing overturning events in the free atmosphere, J. Atmos. Ocean. Tech., 27, 766-775, 2010.

Campos, E., Fabry, F., and Hocking, W.: Precipitation measurements using VHF wind profiler radars: Measuring rainfall and vertical air velocities using only observations with a VHF radar, Radio Sci., 42, RS3003, doi:10.1029/2006RS003540, 2007.

Clayson, C. A. and Kantha, L.: On Turbulence and Mixing in the Free Atmosphere Inferred from High-Resolution Soundings, J. Atmos. Ocean. Tech., 25, 833-852, 2008.

Durran, D. R. and Klemp, J.: On the effects of Moisture on the Brunt-Väisälä Frequency, J. Atmos. Sci., 39, 2152-2158, 1982.

Emanuel, K.: Atmospheric Convection, Oxford University Press, 1994.

Ferron, B., Mercier, H., Speer, K., Gargett, A., and Polzin, K.: Mixing in the Romanche fracture zone, J. Phys. Oceanogr., 28, 19291945, 1998.

Gargett, A. E. and Garner, T.: Determining Thorpe Scales from Ship-Lowered CTD density profiles, J. Atmos. Ocean. Tech., 25, 1657-1670, 2008.

Goff, J.: Saturation pressure of water on the new Kelvin temperature scale, Transactions of the American society of heating and ventilating engineers, 63, 347-354, 1957.

Hirono, M., Luce, H., Yamamoto, M., and Fukao, S.: Horizontal maps of echo power in the lower stratosphere using the MU radar, Ann. Geophys., 22, 717-724, 2004, http://www.ann-geophys.net/22/717/2004/.

Hocking, A. and Hocking, W.: Turbulence Anisotropy Determined by Wind Profiler Radar and Its Correlation with Rain Events in Montreal, Canada, J. Atmos. Ocean. Tech., 24, 40-51, 2007.

Houze, R. A. J.: Cloud Dynamics, Academic Press, 1993.

Johnson, H. L. and Garrett, C.: Effect of noise on Thorpe Scales and run lengths, J. Phys. Oceanogr., 34, 2359-2372, 2004.

Kantha, L. and Hocking, W.: Dissipation rates of turbulence kinetic energy in the free atmosphere: MST radar and radiosondes, J. Atmos. Sol.-Terr. Phys., 73, 1043-1051, 2011.

Lalas, D. and Einaudi, F.: On the correct use of the wet adiabatic lapse rate in stability criteria of a saturated atmosphere, J. Appl. Meteorol., 13, 318-324, 1974.

Luce, H., Hassenpflug, G., Yamamoto, M., and Fukao, S.: Highresolution vertical imaging of the troposphere and lower stratosphere using the new MU radar system, Ann. Geophys., 24, 791804,2006 ,

http://www.ann-geophys.net/24/791/2006/.
Miloshevich, L. M., Paukkunen, A., Vömel, H., and Oltmans, S. J.: Development and Validation of a Time-Lag Correction for Vaisala Radiosonde Humidity Measurements, J. Atmos. Ocean. Tech., 21, 1305-1327, 2004.

Miloshevich, L. M., Vömel, H., Whiteman, D. N., and Leblanc, T.: Accuracy assessment and correction of Vaisala RS92 radiosonde water vapor measurements, J. Geophys. Res., 114, D11305, doi:10.1029/2008JD011565, 2009.

Murphy, D. and Koop, T.: Review of the vapour pressures of ice and supercooled water for atmospheric applications, Q. J. Roy. Meteorol. Soc., 131, 1539-1565, 2005.

Nash, J., Oakley, T., Vömel, H., and Wei, L.: WMO intercomparison of high quality radiosonde systems, Tech. Rep. instruments and observing methods, Report No. 107, World Meteorological Organization, 2010.

Nath, D., Venkat Ratman, M., Patra, A. K., Krishna Murthy, B. V., and Bhaskar Rao, S. V.: Turbulence characteristics over tropical station Gadanki $\left(13.5^{\circ} \mathrm{N}, 79.2^{\circ} \mathrm{E}\right)$ estimated using highresolution GPS radiosonde data, J. Geophys. Res., 115, D07102, doi:10.1029/2009JD012347, 2010.

Poore, K. D., Wang, J., and Rossow, W.: Cloud layer thicknesses from a combination of surface and upper-air observations, J. Climate, 8, 550-568, 1995.

Röttger, J. and Liu, C. H.: Partial reflection and scattering of VHF radar signals from the clear atmosphere, Geophys. Res. Lett., 5, 357-360, 1978.

Thorpe, S. A.: Turbulence and mixing in a Scottish Lock, Philos. T. Roy. Soc. Lond. S, 286, 125-181, 1977.

Vaughan, G. and Worthington, R.: Effects of humidity and precipitation on VHF radar vertical beam echoes, Radio Sci., 35, 13891398, 2000.

Wang, J. and Rossow, W.: Determination of cloud vertical structure from upper-air observations, J. Appl. Meteorol., 34, 2243-2258, 1995.

Wilson, R., Luce, H., Dalaudier, F., and Lefrère, J.: Turbulent Patch Identification in Potential Density/Temperature Profiles, J. Atmos. Ocean. Tech., 26, 977-993, 2010.

Wilson, R., Dalaudier, F., and Luce, H.: Can one detect small-scale turbulence from standard meteorological radiosondes?, Atmos. Meas. Tech., 4, 795-804, doi:10.5194/amt-4-795-2011, 2011.

Worthington, R. M., Palmer, R. D., and Fukao, S.: Complete maps of the aspect sensitivity of VHF atmospheric radar echoes, Ann. Geophys., 17, 1116-1119, 1999, http://www.ann-geophys.net/17/1116/1999/.

Zhang, J., Chen, H., Li, Z., Fan, X., Peng, L., Yu, Y., and Cribb, M.: Analysis of cloud layer structure in Shouxian, China, using RS92 radiosonde aided by $95 \mathrm{GHz}$ cloud radar, J. Geophys. Res., 115, D00K30, doi:10.1029/2010JD014030, 2010. 